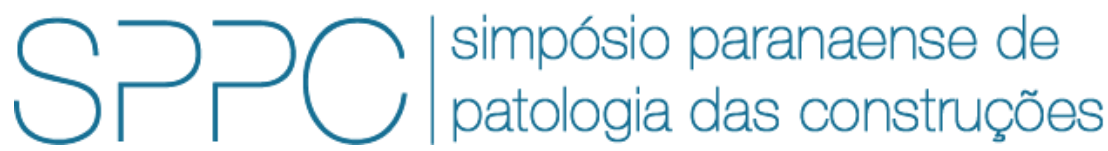

ISSN 2526-7248 artigo 2SPPC1005, pp. 48-56, 2017

\title{
Análise das propriedades de uma argamassa de reparo de base acrílica
}

\author{
Mateus Henrique de Souza ${ }^{1}$ e Rafael Alves de Souza ${ }^{2}$ \\ 1 Engenheiro Civil, Universidade Estadual de Maringá, mateushsouza@outlook.com \\ 2 Professor Titular, Universidade Estadual de Maringá, rsouza@uem.br
}

Resumo: As manifestações patológicas nas estruturas de concreto podem ser causadas por diversos fatores. Entre eles, a falha no material, falha na execução ou até a má utilização. Estes problemas com a estrutura podem afetar o seu desempenho. Como solução para esses problemas, podem ser utilizadas argamassas poliméricas de reparos estrutural. Para isso, faz-se necessário a correta aplicação dos materiais e técnicas para que haja compatibilidade entre o material antigo (substrato) e o novo (reparo). Caso não haja compatibilidade entre os materiais, o reparo pode ser fragilizado e ineficiente. Nesse sentido, o presente trabalho tem por objetivo analisar o comportamento de uma argamassa polimérica de reparo disponível no mercado e comparar as suas vantagens com relação à uma argamassa sem adições (referência). A argamassa comercial estudada é composta por adesivo polimérico de base acrílica. A argamassa de reparo sem adições possui composição básica de cimento e areia quartzosa fina na proporção de 1:3, respectivamente. As propriedades das argamassas no estado endurecido foram testadas por meio de ensaios de compressão e tração por compressão diametral. Foram estudadas também as propriedades de aderência da argamassa de reparo ao substrato, haja visto que uma das principais características do reparo é a sua capacidade de aderência ao material antigo. Após a análise dos resultados pôde-se concluir que a presença de polímeros na argamassa agrega muitos benefícios ao reparo, especialmente a sua capacidade de aderência ao substrato.

Palavras-chave: Reparos em concreto, argamassa polimérica, manifestações patológicas, resistência de aderência.

Abstract: Pathological manifestations in concrete structures may be caused by many factors. These include deficiency of the material, malfunction or even misuse. These problems with a structure can affect its performance. One way to solve these problems is to apply polymeric mortars. However, it is necessary a correct application of the materials and techniques in order to obtain a satisfactory compatibility between the old material (substrate) and the new one (repair). If there is no compatibility between the materials, the repair can be fragile and inefficient. In this sense, the present research has the objective of analyzing the behavior of a polymeric repair mortar available in the market and compares its advantages with respect to a mortar without additions. The selected commercial mortar is composed of polymeric acrylic base. By other hand, the repair mortar without additions has a basic cement composition with fine quartz in the ratio of $1: 3$, respectively. The materials were tested in axial compression and tension (Brazilian test) in the hardened state. It was also studied the properties of adhesion of the repair mortar to the substrate, since it is one of the main desired characteristics. After the analysis of the results it was concluded that the presence of polymers in the mortar improves the repair, especially the ability of adherence to the substrate.

Keywords: Repairs on concrete, polymeric mortar, pathological manifestations, adhesion strength. 


\section{Introdução}

As manifestaçoes patologicas nas estruturas de concreto são muito presentes nas edificações, principalmente pela falta na qualidade dos serviços e materiais. Esses tipos de problemas podem afetar o desempenho e a vida útil das construções [1]. Com isso, é necessario entender as falhas construtivas e os processos que causam deterioração das estruturas de concreto. Com o devido conhecimento das falhas nas estruturas, é necessário então as devidas intervenções técnicas, que tem como objetivo melhorar o desempenho e a vida útil das estruturas.

As manifestações patológicas podem se apresentar nas construções de diversos modos. As principais causas são falhas na execução dos serviços e falhas nos materiais [2]. Ninhos de concretagem e exposição de armadura por falta de espaçadores nas fôrmas são exemplos que corroboram com a afirmação acima. Deste modo, as manifestações patológicas nas estruturas requerem atenção especial no reparo. Principalmente na zona de ligação entre materiais novos e antigos. As falhas nos serviços de reparo podem continuar prejudicando a estrutura, necessitando de retrabalhos [3].

Existem, no mercado, vários produtos que podem solucionar tais manifestações patológicas das estruturas de concreto. Em muitos casos, esses produtos apresentam composições poliméricas, a fim de melhorar o seu desempenho. A presença de polímeros nas argamassas pode contribuir na melhoria das propriedades, tanto no estado fresco, como no estado endurecido. Para esse tipo de utilização, os polímeros mais utilizados são os de base epóxi, PVA (acetato de polivinila), SBR (estireno butadieno) e acrílica [2].

As características alteradas pela adição de adesivos poliméricos em argamassas possibilitam que os reparos nas estruturas de concreto tenham melhor desempenho na sua aplicação. Ao adicionar-se adesivos poliméricos, as propriedades de aderência, plasticidade, coesão, flexibilidade, impermeabilidade e durabilidade são melhoradas, o que permite a execução de reparos em diversas situações [4].

Diante desse cenário, o objetivo deste trabalho é avaliar o comportamento de uma argamassa polimérica de reparo estrutural comercial de base acrílica e compará-la a uma argamassa de reparo sem adições. As propriedades a serem avaliadas serão a resistência à compressão, resistência à tração por compressão diametral e a resistência aderente entre o material de reparo e o material de substrato.

\section{Argamassas poliméricas}

Em se tratando de reparos em estruturas de concreto, um dos materiais mais utilizados são as argamassas alteradas por polímeros, ou então as argamassas poliméricas. Esse tipo de argamassa é composta, normalmente, por cimento Portland, agregados miúdos e adesivos poliméricos. Os polímeros presentes nas argamassas poliméricas têm a função de contribuir com as propriedades mecânicas no estado fresco e endurecido. Com a presença de polímeros, as argamassas de reparo podem possuir melhoras nas resistências mecânicas, aderência ao substrato e 
moldabilidade. Uma propriedade importante, normalmente conferida pela presença de polímeros, é a tixotropia. Essa característica permite que a argamassa seja moldada e utilizada em superfícies verticais e inclinadas [5].

As argamassas poliméricas são de fácil preparo e aplicação, uma vez que são preparadas de modo similar a argamassas e concretos. Alguns dos materiais mais utilizados na composição de argamassas poliméricas são látex, epóxi e PVA [2].

Uma das argamassas poliméricas mais utilizadas são as modificadas por polímeros acrílicos. Esse material possui varias aplicações dentro e fora da construção civil. Os primeiros registros da utilização da resina acrílica datam de 1933. Em 1936 foi introduzida na odontologia, onde obteve grande êxito. Atualmente há diversas outras aplicações para a resina MMA (metil metacrilato), que também é uma identidade da resina acrílica. Sua aplicação vai de lentes de contato, fibras ópticas aos vidros à prova de bala.

$\mathrm{Na}$ construção civil esse material possui grandes e importantes aplicações. Esse fato se confirma na grande aplicação em pisos e revestimentos. Além da estética, esse material garante boa resistência mecânica e química. Essa resina também pode garantir boas propriedades em casos de compósitos cimentícios, principalmente em se tratando de reparos de estruturas.

A resina acrílica é um polímero que, em casos de reparos, pode proporcionar às argamassas, várias vantagens. Esse material possui boa resistência à compressão e boas propriedades aderentes [6]. Além dessas propriedades, esse tipo de adição pode promover a argamassa melhora na trabalhabilidade, redução da porosidade e, consequentemente, redução na absorção de água e redução da penetração de íons de cloreto [7].

De acordo com Aggarwal, Thapliyal e Karade [7], a adição de resinas acrílicas nas argamassas cimentícias induz a uma redução no fator água cimento. Esse fato se explica pela presença de tensoativos e maior tensão de superfície nas moléculas dos polímeros. Além disso, com esse material, é possível a execução de reparos em regiões que sofram com a umidade [2].

\section{Materiais e métodos}

Foram utilizados areia de granulometria fina $(<600 \mu \mathrm{m})$, Cimento Portland do tipo CP II Z 32 e água para a elaboração da argamassa de reparo sem adição (referência). Elaborou-se, também, uma argamassa de reparo estrutural de base acrílica, disponível no mercado.

Para a obtenção da argamassa, utilizou-se de traços indicados na bibliografia [2], na proporção de 1:3 (cimento: areia). A fim de obter-se uma argamassa com propriedades tixotrópicas, utilizou-se água de amassamento suficiente, apenas, para possibilitar a moldagem de esferas com a mão, sem que haja brilho na superfície. $O$ brilho na superfície indica excesso de água [2].

A caracterização das argamassas foi realizada por meio da moldagem de corpos de prova cilíndricos com dimensões $5 \mathrm{~cm}$ de diâmetro por $10 \mathrm{~cm}$ de altura. Esses corpos 
de prova foram testados à compressão e tração por compressão diametral. Além da caracterização dos materiais de reparo, realizou-se a verificação da capacidade aderente desses materiais ao concreto.

Para a verificação da capacidade de aderência dos materiais de reparo em relação ao substrato de concreto, realizou-se uma simulação por meio de corpos de prova cilíndricos compostos de concreto e argamassa. Inicialmente foram moldadas metades de corpos de prova com concreto, que teriam por função simular o substrato a ser reparado. Para a realização do substrato foi utilizado um traço de concreto comum nos canteiros de obra, com resistência estimada para aproximadamente 25 MPa.

Após a cura do concreto, realizou-se a saturação em água da superfície e o preenchimento do corpo de prova com o material de reparo. Na primeira situação utilizou-se a argamassa referência e, na segunda, a argamassa de reparo comercial. Os corpos de prova possuíam dimensões de aproximadamente $10 \mathrm{~cm}$ de diâmetro por $20 \mathrm{~cm}$ de altura.

A verificação da resistência aderente foi realizada por meio de compressão diametral, realizado em linhas diametralmente opostas, no corpo de prova (Figura 1).
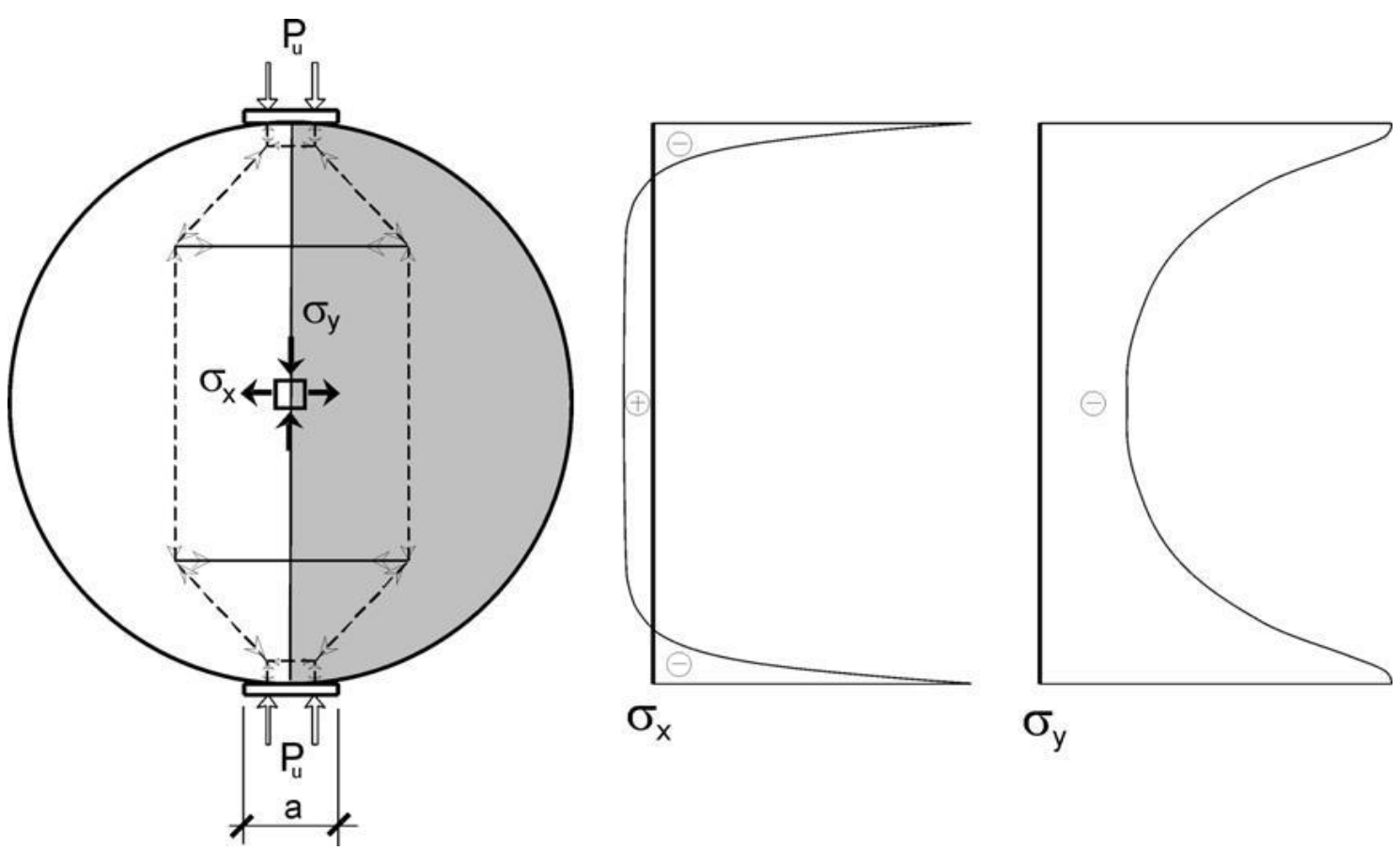

Figura 1: Representação de carregamento e distribuição de tensões na determinação da tração por compressão diametral [8].

Com a obtenção da carga de ruptura, é possível calcular a resistência aderente entre o concreto e as argamassas por meio da equação abaixo retirada da norma ABNT NBR 7222/11 [9] (Eq. 1). 


$$
f_{d}=\frac{2 \cdot F}{\pi \cdot d \cdot L}
$$

Em que:

$f_{d}=$ Resistência aderente entre o concreto e a argamassa (MPa);

$\mathrm{F}=$ Carga máxima obtida no ensaio $(\mathrm{kN})$;

d= Diâmetro do corpo de prova (m);

$L=$ Altura do corpo de prova $(m)$.

\section{Resultados}

Após a realização dos experimentos, obteve-se resultados acerca do concreto que simulou o substrato e também das argamassas de reparo, tanto a referência como a comercial. Os resultados obtidos são apresentados na Tabela 1.

Tabela 1: Propriedades mecânicas do concreto, argamassa referência e argamassa polimérica

\begin{tabular}{cccc}
\hline $\begin{array}{c}\text { Propriedades } \\
\text { avaliadas }\end{array}$ & Concreto & $\begin{array}{c}\text { Argamassa } \\
\text { Referência }\end{array}$ & $\begin{array}{c}\text { Argamassa } \\
\text { Polimérica }\end{array}$ \\
\hline $\begin{array}{c}\text { Resistência média à } \\
\text { compressão aos } 28 \\
\text { dias (MPa) }\end{array}$ & 23,80 & 19,34 & 25,61 \\
\hline $\begin{array}{c}\text { Resistência média à } \\
\text { tração por } \\
\text { compressão } \\
\text { diametral aos } 28\end{array}$ & 2,51 & 2,00 & 3,50 \\
dias (MPa) & & & \\
\hline
\end{tabular}

Nota-se que as resistências à compressão e à tração da argamassa polimérica são superiores aos valores obtidos para o concreto e para a argamassa referência (sem adições). Apesar de superior, os valores da argamassa polimérica estão próximos aos valores do concreto, indicando compatibilidade entre os materiais. De maneira geral, recomenda-se que as propriedades dos materiais antigos (substrato) e novos (reparo) sejam compatíveis para que o reparo tenha bom desempenho [10-11].

Além de avaliar os materiais separadamente, realizou-se um ensaio com o propósito de avaliar a aderência entre o material de reparo e o concreto do substrato. Conforme apresentado anteriormente, verificou-se os valores de aderência por meio da 
aplicação de carga em linhas diametralmente opostas, no corpo de prova cilíndrico. Avaliou-se a aderência após a aplicação do reparo em superfície de concreto saturada. Os valores obtidos estão dispostos na

Tabela 2.

Tabela 2: Resistência aderente entre o concreto e as argamassas

\begin{tabular}{ccc}
\hline Propriedade avaliada & $\begin{array}{c}\text { Argamassa } \\
\text { Referência }\end{array}$ & $\begin{array}{c}\text { Argamassa } \\
\text { Polimérica }\end{array}$ \\
\hline $\begin{array}{c}\text { Resistência aderente por } \\
\text { compressão diametral (MPa) }\end{array}$ & 0,76 & 2,6 \\
\hline
\end{tabular}

Os resultados indicam uma melhora da resistência aderente entre o concreto e a argamassa referência. A ação da composição polimérica para reparo estrutural influencia diretamente na capacidade de aderência entre o material novo e o antigo. De acordo com estudos realizados, existem parâmetros de comparação para definir a qualidade de ligação, conforme apresentado na Tabela 3.

Tabela 3: Qualidade da resistência de aderência entre o reparo e o substrato [10].

\begin{tabular}{lc}
\hline $\begin{array}{c}\text { Qualidade da } \\
\text { ligação }\end{array}$ & $\begin{array}{c}\text { Tensão de } \\
\text { ligação (MPa) }\end{array}$ \\
\hline Excelente & $\geq 2,1$ \\
\hline Muito boa & $1,7-2,1$ \\
\hline Boa & $1,4-1,7$ \\
\hline Regular & $0,7-1,4$ \\
\hline Ruim & $0-0,7$ \\
\hline
\end{tabular}

De acordo com os valores apresentados na tabela acima (Tabela 3), observa-se que que a argamassa polimérica estudada neste trabalho apresenta excelente capacidade aderente ao substrato. Entretanto, a argamassa sem adições de polímeros apresenta uma qualidade regular para aderência.

As imagens registradas dos corpos de prova após o ensaio indicam que houve falha parcial dos materiais (concreto e argamassa), conforme ilustra a Figura 2. Contudo, a maior área de ruptura, para os corpos de prova, é referente à argamassa. Todos os corpos de prova rompidos na aderência apresentaram o mesmo tipo de ruptura. 


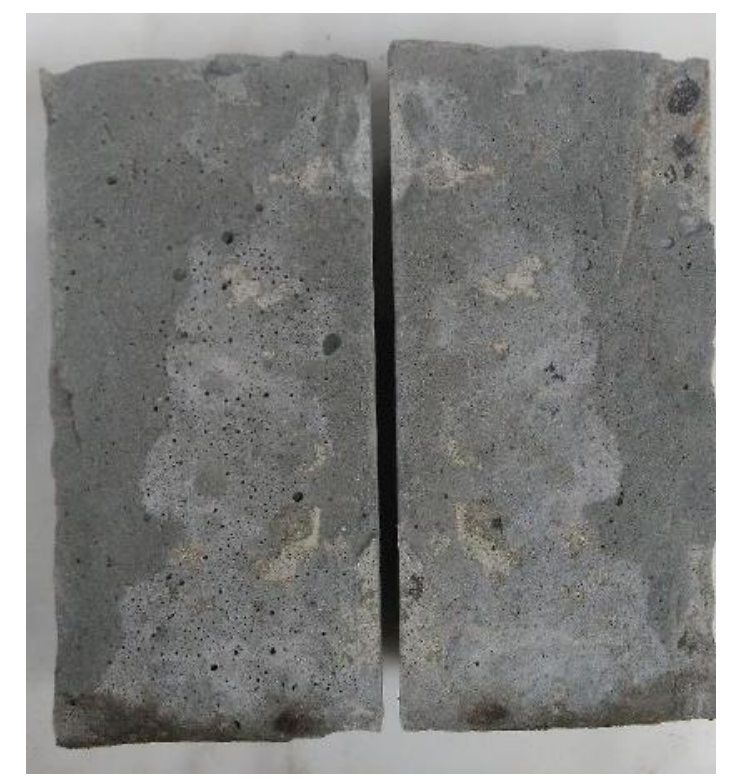

Figura 2: Superfícies do corpo de prova ensaiado na aderência

Ao comparar-se os dois materiais de reparo analisados neste trabalho, observa-se a superioridade dos valores obtidos para a argamassa modificada em relação a argamassa sem adição. A Figura 3 ilustra a comparação entre os resultados obtidos para a argamassa sem adição e a argamassa modificada por polímero acrílico.

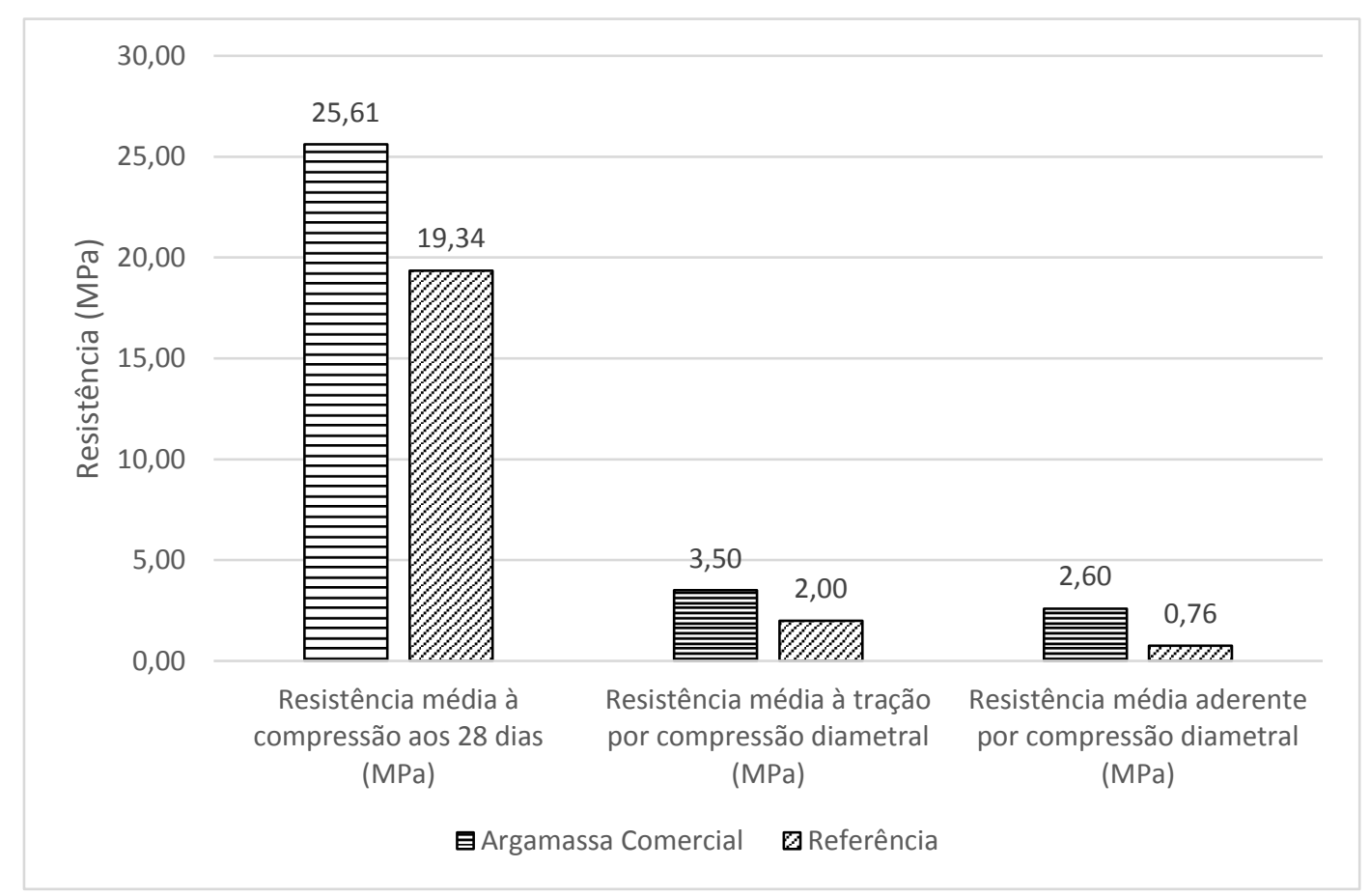

Figura 3: Comparativo gráfico das propriedades mecânicas da argamassa comercial e referência

A modificação de argamassas de reparo são necessárias para que haja, efetivamente, a reabilitação da estrutura. A face de ligação entre os materiais de idades diferentes requerem cuidados especiais, pois, essa região de transição é muito frágil [11]. 


\section{Conclusão}

Com a análise dos resultados, observou-se que o desempenho da aderência da argamassa polimérica de reparo estrutural de base acrílica foi melhor que a argamassa para reparo sem adições. Neste sentido, é possível observar a importância e os benefícios que os adesivos poliméricos propiciam aos materiais, especialmente os de reparo. Como observado, para que haja um bom desempenho do reparo, suas propriedades devem ser compatíveis com o material do substrato, além de possuir boa aderência ao mesmo. Uma falha na aderência pode permitir o acesso de agentes deterioradores da estrutura, o que fragilizaria a região reparada.

As propriedades estudadas (resistência à compressão, tração e aderência), referentes à argamassa de base acrílica, apresentaram ótimo comportamento em relação à argamassa referência. Por não possuir ponte de aderência entre os materiais de substrato e reparo, os resultados mostram a capacidade aderente pura das argamassas em relação ao concreto. Desta forma, o objetivo do trabalho, que foi verificar as propriedades da argamassa comercial de reparo de base acrílica e uma argamassa de reparo sem adição, foi atingido.

\section{Agradecimentos}

Os agradecimentos são para a CAPES, pelo apoio financeiro e pelo Programa de Pós-Graduação em Engenharia Urbana da Universidade Estadual de Maringá.

\section{Referências}

[1] Geiker, M. R. (2012) On the importance of execution for obtaining the designed durability of reinforced concrete structures: Construction of durable concrete structures, Materials and corrosión, 63: 1114 -1118.

[2] Souza, V. C. M.; Ripper, T. (1998) Patologia, Recuperação e Reforço de Estruturas de Concreto, $1^{1}$ ed., São Paulo: Pini.

[3] Luković, M.; Šavija, B.; Dong, H.; Schlangen, E.; Ye, G. (2014) Micromechanical study of the interface properties in concrete repair systems, Journal of Advanced Concrete Technology, 12: 320-339.

[4] Soufi, A.; Mahieux, P.-Y.; Aı̈t-Mokhtar, A.; Amiri, O. (2016) Influence of polymer proportion on transfer properties of repair mortars having equivalent water porosity, Materials and Structures, 49: 383-398.

[5] Helene, P. R. L. (1992) Manual para reparo, reforço e proteção de Estruturas de Concreto, São Paulo, SP: PINI.

[6] Medeiros, M.; Helene, P.; Selmo, S. (2009) Influence of EVA and acrylate polymers on some mechanical properties of cementitious repair mortars, Construction and Building Materials, 23: 2527-2533. 
[7] Aggarwal, L.; Thapliyal, P.; Karade, S. (2007) Properties of polymer-modified mortars using epoxy and acrylic emulsions, Construction and Building Materials, 21: 379-383.

[9] NBR 7222 (2011) Concreto e argamassa - Determinação da resistência à tração por compressão diametral de corpos de prova cilíndricos. Associação Brasileira de Normas Técnicas - ABNT, Rio de Janeiro, Brasil.

[10] Sprinkel, M. M.; Ozyildirim, C. (2000) EVALUATION OF HIGH PERFORMANCE CONCRETE OVERLAYS PLACED, Virginia Department of Transportation, Charlottesville, Virginia, USA.

[11] Ueda, H.; Tamai, Y.; Kudo, T. (2011) Evaluation of the Durability of Cementbased Repair Materials, Railway Technical Research Institute, 52: 92-96. 